\title{
Epigenetic variation reflects dynamic habitat conditions in a rare floodplain herb
}

\author{
BENJAMIN SCHULZ, * ROLF LUTZ ECKSTEIN* and WALTER DURKA $\dagger$ \\ *Institute of Landscape Ecology and Resource Management, Interdisciplinary Research Centre (IFZ), Justus Liebig University \\ Giessen, Heinrich-Buff-Ring 26-32, D-35393 Giessen, Germany, †Department of Community Ecology (BZF), Helmholtz Centre \\ for Environmental Research-UFZ, Theodor-Lieser-Straße 4, D-06120 Halle (Saale), Germany
}

\begin{abstract}
Variation of DNA methylation is thought to play an important role for rapid adjustments of plant populations to dynamic environmental conditions, thus compensating for the relatively slow response time of genetic adaptations. However, genetic and epigenetic variation of wild plant populations has not yet been directly compared in fast changing environments. Here, we surveyed populations of Viola elatior from two adjacent habitat types along a successional gradient characterized by strong differences in light availability. Using amplified fragment length polymorphisms (AFLP) and methylation-sensitive amplification polymorphisms (MSAP) analyses, we found relatively low levels of genetic $\left(H^{\prime}\right.$ gen $\left.=0.19\right)$ and epigenetic $\left(H_{\text {epi }}^{\prime}=0.23\right)$ diversity and high genetic $\left(\phi_{\mathrm{ST}}=0.72\right)$ and epigenetic $\left(\phi_{\mathrm{ST}}=0.51\right)$ population differentiation. Diversity and differentiation were significantly correlated, suggesting that epigenetic variation partly depends on the same driving forces as genetic variation. Correlation-based genome scans detected comparable levels of genetic $(\mathbf{1 7 . 0 \% )}$ ) and epigenetic $(\mathbf{1 4 . 2 \%})$ outlier markers associated with site specific light availability. However, as revealed by separate differentiation-based genome scans for AFLP, only few genetic markers seemed to be actually under positive selection $(0-4.5 \%)$. Moreover, principal coordinates analyses and Mantel tests showed that overall epigenetic variation was more closely related to habitat conditions, indicating that environmentally induced methylation changes may lead to convergence of populations experiencing similar habitat conditions and thus may play a major role for the transient and/or heritable adjustment to changing environments. Additionally, using a new MSAP-scoring approach, we found that mainly the unmethylated $\left(\phi_{\mathrm{ST}}=0.60\right)$ and CG-methylated states $\left(\phi_{\mathrm{ST}}=0.46\right)$ of epiloci contributed to population differentiation and putative habitat-related adaptation, whereas CHG-hemimethylated states $\left(\phi_{\mathrm{ST}}=0.21\right)$ only played a marginal role.

Keywords: AFLP, ecological epigenetics, environmental gradient, methylation, MSAP, Viola elatior
\end{abstract}

Received 18 December 2013; revision received 5 June 2014; accepted 6 June 2014

\section{Introduction}

To cope with spatial heterogeneity and temporal dynamics of their habitats, plants as sessile organisms constantly need to respond to varying environmental conditions. While slow adaptation of morphology, physiology or development can be attained by genetic

Correspondence: Benjamin Schulz, Fax: +49 (0)641 9937169;

E-mail: Benjamin.Schulz@umwelt.uni-giessen.de changes through mutation, drift and selection, rapid responses to biotic or abiotic alterations necessitate alternative regulations (Boyko \& Kovalchuk 2011). As an alternative to 'hard-' or 'Mendelian inheritance', 'soft inheritance' through epigenetic mechanisms has been proposed to fill this gap between random genetic and environmental variation (Richards 2006). Epigenetic silencing or activation of protein coding genes, which is sensitive to environmental variation, may convert environmental heterogeneity into phenotypic differences 
(Flores et al. 2013). These epigenetically induced phenotypic changes can then be inherited through meiosis over several generations (reviewed in Jablonka \& Raz 2009), giving rise to so-called epialleles. Furthermore, due to its semi-stable nature, inherited epigenetic variation is suited to plastically react to environmental fluctuations that last for only few generations. Especially in long-lived perennials and species that mainly reproduce vegetatively or through self-pollination, such fast adjustment through epigenetic processes seems essential to ensure continued survival of populations under episodic stress (Castonguay \& Angers 2012; Bräutigam et al. 2013).

An array of epigenetic mechanisms has been identified, including chemical modification of DNA and histones, position effects and interference by small non-coding RNAs (Berger 2007). Without changing the underlying DNA sequence, these mechanisms can rapidly modulate existing genetic information through the control of gene expression or the reorganization of chromatin structure (Sahu et al. 2013). The most extensively studied and best understood epigenetic mechanism is the potentially reversible methylation of DNA, which in higher eukaryotes mainly involves the methylation of cytosine residues (Feng et al. 2010). In plants, cytosine methylations are found throughout the genome in three different sequence contexts, symmetric CG and CHG sites $(\mathrm{H}=\mathrm{A}, \mathrm{C}, \mathrm{T})$ and asymmetric $\mathrm{CHH}$ sites. Methylations in all three contexts are predominantly found in transposable elements and repetitive sequences where they generally are related to transcriptional repression (Saze et al. 2012).

Various studies have shown that the amount and pattern of DNA methylation in plants is sensitive to biotic and abiotic stressors such as pathogens (Wada et al. 2004), herbivores (Herrera \& Bazaga 2013), drought (Labra et al. 2002), extreme temperatures (Boyko et al. 2010) or nutrient availability (Boyko et al. 2010; Kou et al. 2011). Depending on the species, genotype and environmental cue, stress treatments induced hypo- or hypermethylation or balanced shifts in global methylation patterns that in some cases were stably transmitted to the next generation (e.g. Verhoeven et al. 2010; Kou et al. 2011). Recent studies even directly correlated stress-induced inherited changes of DNA methylation with adaptive plant responses to salt stress (Boyko et al. 2010) or high temperature (Correia et al. 2013). Taken together, the inheritance and the adaptive value of stress-induced alterations in DNA methylations strongly support the idea of an epigenetically regulated system of 'soft inheritance' (Zhang et al. 2013).

However, there is still a dearth of studies that explore the extent of epigenetic variation and its adaptive potential in natural populations (Angers et al. 2010; Latzel et al. 2013). Moreover, whereas previous surveys mostly focused on species with very little or no genetic variation (e.g. Richards et al. 2012; Yu et al. 2013), improving the ability to attribute epigenetic variation to specific environmental conditions (Ledon-Rettig 2013), only few studies compared the impact of genetic and epigenetic variation in genetically diverse species (Herrera \& Bazaga 2010; Lira-Medeiros et al. 2010; Abratowska et al. 2012; Wu et al. 2013). However, most plant populations are genetically diverse, implying a complex relationship between genetic, epigenetic and environmental variation. Indeed, the available studies found a certain correlation between genetic and epigenetic variation, but also revealed that epigenetic differentiation was more closely aligned with the environment than genetic differentiation (Lira-Medeiros et al. 2010; Abratowska et al. 2012), suggesting that heritable epigenetic changes might play an important role for local adaptation. However, all of the investigated habitats represented temporally stable conditions that persisted for long periods of time (e.g. differences in salinity, heavy metal content or altitude), potentially resulting in extensive genetic adaptation. Hence, this complicates the study of epigenetically based 'soft inheritance' as a mechanism for rapid and independent environmental adjustment. Consequently, there is a need for studies that focus on more dynamic, faster changing systems that are less probably to allow for genetic adaptation.

One such fast changing environmental parameter is the decreasing light availability along successional gradients. Both, quality and quantity of light may have effects on DNA methylation (Tatra et al. 2000; Greco et al. 2013). Moreover, as light is a strong environmental cue, influencing an array of other biotic and abiotic parameters (e.g. competition, water availability or temperature) a high selection pressure is expected under changing light conditions, making successional gradients an ideal study system to compare genetic and epigenetic variation in response to fast changing environments.

To assess methylation variation of large numbers of individuals, population studies mostly use methylationsensitive amplification polymorphisms (MSAP) that essentially can differentiate unmethylated, CG-methylated and CHG-hemimethylated states of particular epiloci (Salmon et al. 2008). However, for statistical analyses, most previous studies combined the two discernible methylation types into one common state, ignoring regulatory and potential functional differences. Moreover, unmethylated states are generally not considered, thus missing further resolution and information about the putatively active state of the epigenome (Schulz et al. 2013). Consequently, there is a need for studies that consider all three MSAP fragment types and thus potentially enable more detailed insights into epigenetic processes. 
Here, we investigated genetic and epigenetic variation of Viola elatior in two adjacent habitat types along a successional gradient characterized by strong differences in light availability. Using amplified fragment length polymorphisms (AFLP) and MSAP and applying genome scan approaches to detect putatively adaptive genetic and epigenetic outlier loci, we asked the following questions: (i) Do genetic and epigenetic variation contribute differentially to habitat-related differentiation? (ii) Are epigenetic differences between habitat types consistent among regions and thus potentially decoupled from genetic variation? (iii) How do different methylation types (i.e. unmethylated, CG-methylated or CHG-hemimethylated fragments) contribute to epigenetic population structuring?

\section{Material and methods}

\section{Study species}

Viola elatior (Violaceae) is a perennial iteroparous hemicryptophyte. In Central Europe, the species is restricted to different floodplain habitats ranging from floodplain meadows to alluvial woodland fringes, characterized by changing environmental conditions due to disturbance and succession (Eckstein \& Otte 2005; Eckstein et al. 2006). These environmental changes may proceed rather fast, encompassing a time span of only few plant generations. Although $V$. elatior survives under a wide range of light conditions, with increasing succession to closed alluvial forests, population sizes decline and the species finally disappears (Eckstein et al. 2006). However, due to its persistent seed bank, after major disturbance events, populations may recover even after years of absence from the above-ground vegetation (Eckstein et al. 2006). In Germany, the species is rare and endangered with populations of varying sizes from tens to several hundred individuals. The species is octoploid $(2 n=40)$ and exhibits a mixed mating system with potentially cross-pollinated chasmogamous $(\mathrm{CH})$ and obligatory self-pollinated cleistogamous (CL) flowers (Eckstein et al. 2006). Nonetheless, seed production through CL-flowers is dominating. In common garden experiments only around $4 \%$ of capsules were produced by $\mathrm{CH}$-flowers (Eckstein \& Otte 2005; B. Schulz, unpublished), suggesting a high selfing rate also in natural populations. Additionally, vegetative reproduction by disintegration of old pleiocorms or formation of root buds occurs (Eckstein et al. 2006).

\section{Sampling design}

The study was conducted with six stands (hereafter called populations) from the Upper Rhine Valley located in the nature reserves 'Kühkopf-Knoblochsaue' (K) and 'Lampertheimer Altrhein' (L) near Frankfurt, Germany (Fig. 1). First, all known populations of $V$. elatior in the two regions were visually classified according to their light environment. Then, populations for the two extremes of the species' environmental range, that is, sunny floodplain meadows (M) and shady alluvial woodland fringes (W), were selected. Due to limited numbers of appropriate populations in the different habitat types with more than 20 individuals, we chose two $\mathrm{M}$ - and one $\mathrm{W}$-site in region $\mathrm{K}$ and one $\mathrm{M}$ - and two $\mathrm{W}$-sites in region $\mathrm{L}$ (Fig. 1, Table 1). Distance between regions is $25 \mathrm{~km}$ and within regions, distances between populations range between 0.5 and $4 \mathrm{~km}$.

After mapping $V$. elatior at each site on a $1 \mathrm{~m}$ grid, 20-25 populated grid cells were randomly selected and young undamaged leaves from one reproductive plant per cell were collected. Samples were immediately cooled to below $10{ }^{\circ} \mathrm{C}$, stored at $-25^{\circ} \mathrm{C}$ and freezedried for $48 \mathrm{~h}$.

\section{Light availability}

Mean transmitted photosynthetic active radiation (PAR) per site was assessed with hemispherical photography. At each site, 20 digital hemispherical photographs were taken in randomly selected populated grid cells (i.e. independent from plant sampling) with a Nikon CoolPix 4500 camera and a Fish-eye converter lens FC-E8 (Nikon, Tokyo, Japan) mounted on a tripod $70 \mathrm{~cm}$ above ground. Aperture and exposure time were fitted following the study of Zhang et al. (2005). Images were converted to black and white bitmaps using automatic threshold detection algorithms with SIDELOOK 1.1.01 (Nobis \& Hunziker 2005) and then analysed using GAP LIGHT ANALYZER (GLA) 2.0 (Frazer et al. 1999). Light availability for each site was subsequently quantified as mean daily percentage of transmitted total PAR for the period from 1 May to 30 September averaged across the 20 images (Table 1).

\section{AFLP genotyping and MSAP epigenotyping}

We investigated a total of 132 individuals for genetic and epigenetic variation with AFLP and MSAP. For each individual, the same DNA sample was used for both approaches. Total genomic DNA was extracted from dried leaf tissue using the DNeasy 96 Plant extraction Kit (QIAGEN). AFLP and MSAP methodology followed the protocol as described in Appendix S1 (Supporting information), using eight selective primer combinations, respectively (Table S1, Supporting information). 


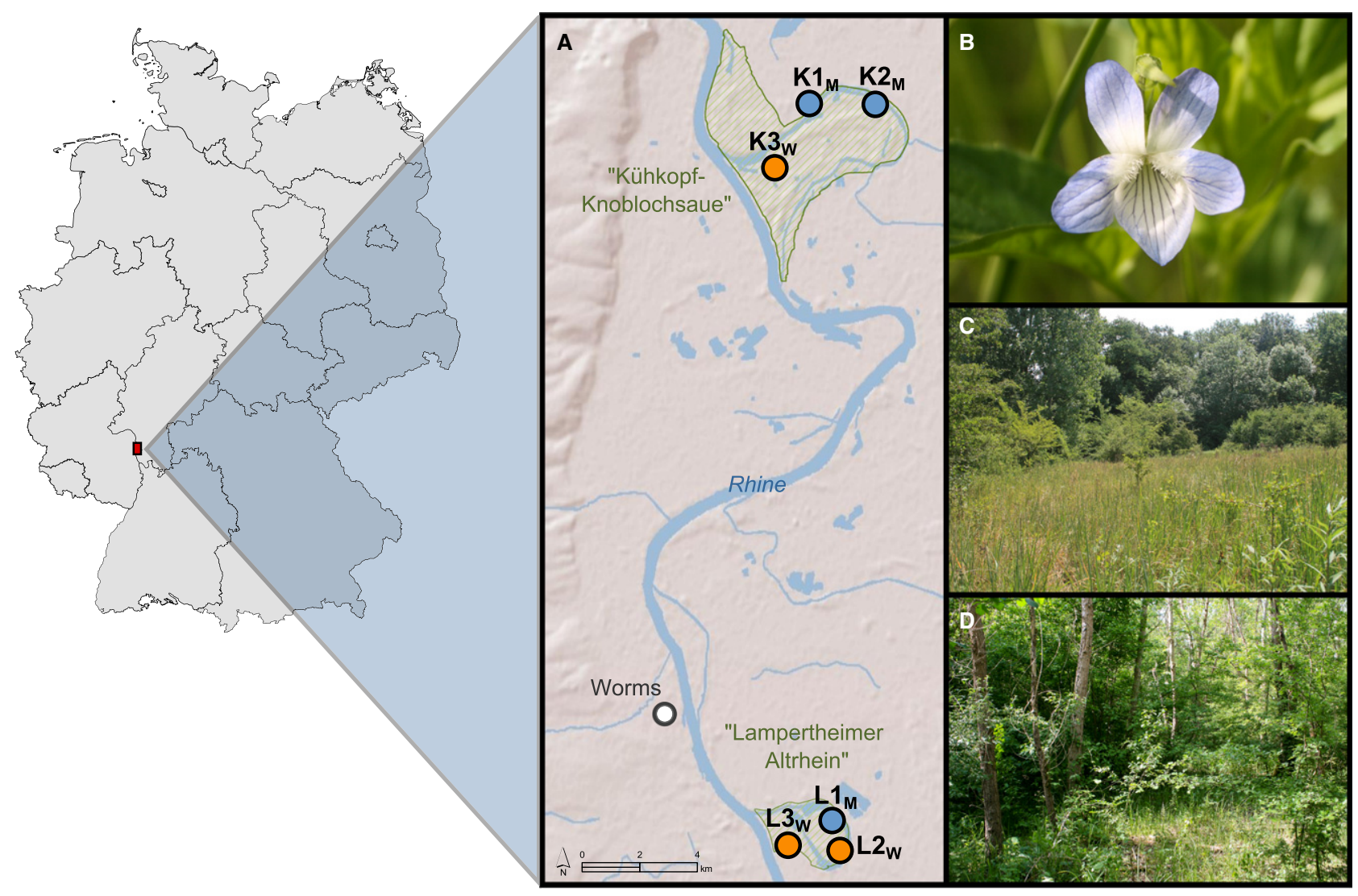

Fig. 1 Location and study sites. (A) Section of the Upper Rhine Valley south of Frankfurt/Main, Germany, with the six sampled populations of Viola elatior in the nature reserves Kühkopf-Knoblochsaue and Lampertheimer Altrhein. Symbol colours indicate the habitat type (blue $=$ meadow, brown $=$ woodland). $(B)$ Viola elatior flower. $(C, D)$ Surveyed habitat types with strong differences in light availability: (C) floodplain meadow, (D) alluvial woodland fringe.

Table 1 Overview of sampled populations of Viola elatior

\begin{tabular}{|c|c|c|c|c|c|c|c|}
\hline Population ID & Region & Latitude & Longitude & $\begin{array}{l}\text { Sample } \\
\text { number }\end{array}$ & $\begin{array}{l}\text { Populated grid } \\
\text { cells }\left(\mathrm{m}^{2}\right)\end{array}$ & Habitat Type & $\begin{array}{l}\text { Mean transmitted } \\
\text { photosynthetic active } \\
\text { radiation } \pm \text { SD }(\%)\end{array}$ \\
\hline $\mathrm{K} 1_{\mathrm{M}}$ & Kühkopf-Knoblochsaue & $49^{\circ} 50^{\prime} 01^{\prime \prime} \mathrm{N}$ & $8^{\circ} 25^{\prime} 32^{\prime \prime} \mathrm{E}$ & 20 & $\sim 1400$ & Meadow & $87.8 \pm 6.5$ \\
\hline $\mathrm{K} 2_{\mathrm{M}}$ & Kühkopf-Knoblochsaue & $49^{\circ} 49^{\prime} 49^{\prime \prime} \mathrm{N}$ & $8^{\circ} 28^{\prime} 03^{\prime \prime} \mathrm{E}$ & 20 & 159 & Meadow & $73.8 \pm 8.3$ \\
\hline $\mathrm{K} 3_{\mathrm{W}}$ & Kühkopf-Knoblochsaue & $49^{\circ} 48^{\prime} 50^{\prime \prime} \mathrm{N}$ & $8^{\circ} 24^{\prime} 57^{\prime \prime} \mathrm{E}$ & 25 & 158 & Woodland & $23.6 \pm 14.2$ \\
\hline $\mathrm{L} 1_{\mathrm{M}}$ & Lampertheimer Altrhein & $49^{\circ} 36^{\prime} 08^{\prime \prime} \mathrm{N}$ & $8^{\circ} 26^{\prime} 50^{\prime \prime} \mathrm{E}$ & 22 & 170 & Meadow & $80.5 \pm 14.7$ \\
\hline $\mathrm{L} 2 \mathrm{~W}$ & Lampertheimer Altrhein & $49^{\circ} 35^{\prime} 49^{\prime \prime} \mathrm{N}$ & $8^{\circ} 26^{\prime} 50^{\prime \prime} \mathrm{E}$ & 24 & 31 & Woodland & $12.5 \pm 3.3$ \\
\hline $\mathrm{L} 3{ }_{\mathrm{W}}$ & Lampertheimer Altrhein & $49^{\circ} 35^{\prime} 44^{\prime \prime} \mathrm{N}$ & $8^{\circ} 25^{\prime} 55^{\prime \prime} \mathrm{E}$ & 21 & 144 & Woodland & $16.5 \pm 9.4$ \\
\hline
\end{tabular}

For MSAP analyses, comparison of the banding patterns of EcoRI/HpaII and EcoRI/MspI reactions results in four conditions of a particular fragment: $I=$ fragments present in both profiles (1/1), indicating an unmethylated state; II = fragments present only in EcoRI/MspI profiles (0/1), indicating hemi- or fully methylated CG-sites; $\mathrm{III}=$ fragments present only in EcoRI/HpaII profiles (1/0), indicating hemimethylated CHG-sites; IV $=$ absence of fragments in both profiles
$(0 / 0)$, representing an uninformative state caused either by different types of methylation or due to restriction site polymorphism. To separate unmethylated and methylated fragments and to test for the particular impact of the methylated conditions II and III, we used the 'Mixed-Scoring 2' approach (Schulz et al. 2013). This approach generates the final epigenetic data matrix by transforming the three discernible methylation states at each multistate epilocus into separate binary subepiloci, 
thereby keeping all available information and allowing for fragment specific analyses. Thus, for a particular epilocus, up to three subepiloci are generated, coding the nonmethylated (n-subepiloci), the CG-methylated (m-subepiloci) and the CHG-hemimethylated state (hsubepiloci). For a detailed description of the steps of epigenotyping, see Schulz et al. (2013). Overall error rate for AFLP and MSAP data was 3.3\% and 2.1\%, respectively, based on 33 replicate samples.

\section{Data analysis}

Binary AFLP and MSAP data sets were analysed following the same framework using a band- or marker-based strategy, that is, without calculating allele frequencies (Bonin et al. 2007). Genetic and epigenetic diversity within populations were quantified using the R SCRIPT MSAP_CALC (Schulz et al. 2013) as (i) percentage of total and private bands and (ii) percentage of polymorphic loci $\left(P L P_{\text {gen }}\right)$ and subepiloci $\left(P L P_{\text {epi }}\right)$ and (iii) mean Shannon's information index $H_{\text {gen }}^{\prime}$ and $H^{\prime}{ }_{\text {epi }}$.

Patterns of individual relationships were depicted by principal coordinates analyses (PCOA) with GENALEX 6.41 (Peakall \& Smouse 2006) based on a matrix of Nei and Li distances calculated with DISTAFLP (Mougel et al. 2002). Distance matrices were square root transformed to meet the assumptions of PCoA analyses (Legendre \& Legendre 1998).

Genetic and epigenetic variation among groups of populations $\left(\phi_{\mathrm{CT}}\right)$, among populations within groups $\left(\phi_{\mathrm{SC}}\right)$ and within populations $\left(\phi_{\mathrm{ST}}\right)$ was partitioned with hierarchical analysis of molecular variance (AMOVA) using ARLEQUIN 3.5.1.2 (Excoffier \& Lischer 2010). Additionally, pairwise $\phi_{\mathrm{ST}}$ values were estimated among populations. Significance levels were determined after 9999 permutations.

To evaluate the relationships between geography and habitat type and genetic and epigenetic differentiation, we conducted pairwise and partial Mantel tests using the 'vegan' library in R (Oksanen et al. 2007) with 999 permutations. We used Euclidian geographic distances, and for habitat types, we constructed a matrix coding pairs of meadow-woodland populations by ' 1 ' and pairs of equal habitats by ' 0 '.

To detect signatures of light-related adaptation in the genetic and epigenetic data sets, we used the Spatial Analysis Method (SAM; Joost et al. 2007), which uses multiple univariate logistic regression. In our case, the site-specific mean values of percentage of transmitted PAR (Table 1) were assigned to genetic and epigenetic marker data of all individuals from one population. SAM uses the individual as reference unit, functions independently of any presumed population structure and is largely assumption free (Joost et al. 2007; Paun et al.
2010). Only if the two statistical tests implemented in SAM (likelihood ratio $G$ and Wald test) reject the null hypothesis, a model is considered significant (Joost et al. 2007). Bonferroni correction of the significance level for multiple comparisons was applied corresponding to a 95\% and $99 \%$ confidence interval (CI).

To depict effects of putatively adaptive markers on population structure, AFLP and MSAP data sets were partitioned into subsets of neutral and outlier markers (95\% CI) and were then visualized with PCoA as described previously. For MSAP data, corresponding $\mathrm{n}$-, m- or h-subepiloci (i.e. resulting from one epilocus) were jointly excluded from the neutral data set when at least one of them was classified as an outlier.

To obtain further information on the degree of positive selection at the genetic level, we used two differentiation based genome scan approaches on the AFLP data: DFDIST/FDIST (Beaumont \& Balding 2004) as included in the workbench MCHEZA (Antao \& Beaumont 2011) and BAYESCAN 2.1 (Foll \& Gaggiotti 2008). DFDIST/ FDIST analyses in MCHEZA were conducted with 50000 simulations, using the combined 'Neutral mean $F_{\mathrm{ST}}$ ' and 'Force mean $F_{\mathrm{ST}}$ ' algorithms and two detection levels at $95 \%$ and $99 \%$ CI. Results were corrected for multiple comparisons by setting false discovery rate to 0.1 . BAYESCAN analyses were run with a burn-in of 50000 iterations, a sample size of 10000 and a thinning interval of 50, resulting in a total of 550000 iterations. An additional burn-in was carried out by 20 short pilot runs of 5000 iterations. Only loci exceeding a 'strong' detection level (Bayesian factor BF $>10$ ) were considered as putative outliers.

\section{Results}

\section{Genetic and epigenetic diversity}

The AFLP analysis resulted in 428 scorable loci of which $112(26 \%)$ were polymorphic. Across all individuals, 106 unique AFLP phenotypes were found, that is, $20 \%$ of individuals had shared AFLP phenotypes, ranging from $10 \%$ in $\mathrm{K} 1_{\mathrm{M}}$ to $42 \%$ in $\mathrm{L} 2 \mathrm{~W}$. Within populations, between one and four AFLP phenotypes were shared by more than one individual (Table 2). As the mean distance between individuals with shared AFLP phenotypes was $14.1 \mathrm{~m}$ and only six of 49 pairs were separated by $<3 \mathrm{~m}$, we assumed that the majority of pairs do not represent vegetative clones but closely related, inbred individuals. Thus, all individuals were retained in the subsequent analyses. Assessment of genetic diversity across populations (Table 2 ) revealed mean values of $67.7 \%$ for percentage of bands present, $2.7 \%$ for private bands, $37.5 \%$ for $P L P_{\text {gen }}$ and 0.19 for $H_{\text {gen }}^{\prime}$ 
Table 2 Measures of genetic and epigenetic diversity within six populations of Viola elatior

\begin{tabular}{|c|c|c|c|c|c|}
\hline & AFLP & MSAP all & MSAP n-subepiloci & MSAP m-subepiloci & MSAP h-subepiloci \\
\hline Polymorphic loci & 112 & 444 & 207 & 157 & 80 \\
\hline \multicolumn{6}{|c|}{ Phenotypes per population* } \\
\hline $\mathrm{K} 1_{\mathrm{M}}(n=20)$ & $18(2)$ & 20 & 20 & 20 & 20 \\
\hline $\mathrm{K} 2_{\mathrm{M}}(n=20)$ & $14(4)$ & 20 & 20 & 20 & 20 \\
\hline $\mathrm{K} 3_{\mathrm{W}}(n=25)$ & $22(1)$ & 25 & 25 & 25 & 25 \\
\hline $\mathrm{L}_{\mathrm{M}}(n=22)$ & $19(2)$ & 22 & 22 & 22 & 22 \\
\hline $\mathrm{L} 2_{\mathrm{W}}(n=24)$ & $14(4)$ & 24 & 24 & 24 & 24 \\
\hline $\mathrm{L}_{\mathrm{W}}(n=21)$ & $18(1)$ & 21 & 21 & 21 & 21 \\
\hline \multicolumn{6}{|c|}{ Bands per population $(\%)$} \\
\hline $\mathrm{K} 1_{\mathrm{M}}$ & 62.5 & 61.7 & 61.4 & 72.6 & 41.3 \\
\hline $\mathrm{K} 2_{\mathrm{M}}$ & 75.9 & 70.9 & 74.4 & 72.6 & 58.8 \\
\hline $\mathrm{K} 3_{\mathrm{w}}$ & 67.0 & 63.7 & 61.8 & 68.8 & 58.8 \\
\hline $\mathrm{L} 1_{\mathrm{M}}$ & 67.9 & 56.1 & 54.6 & 63.7 & 45.0 \\
\hline $\mathrm{L} 2 \mathrm{~W}$ & 61.6 & 52.3 & 51.7 & 61.1 & 36.3 \\
\hline $\mathrm{L} 3_{W}$ & 71.4 & 62.2 & 63.8 & 67.5 & 47.5 \\
\hline Mean & 67.7 & 61.1 & 61.3 & 67.7 & 47.9 \\
\hline \multicolumn{6}{|c|}{ Private bands per population (\%) } \\
\hline $\mathrm{K} 1_{\mathrm{M}}$ & 2.7 & 1.6 & 1.4 & 1.9 & 1.3 \\
\hline $\mathrm{K} 2_{\mathrm{M}}$ & 3.6 & 5.4 & 5.8 & 4.5 & 6.3 \\
\hline $\mathrm{K} 3_{\mathrm{W}}$ & 0.0 & 2.9 & 2.9 & 1.3 & 6.3 \\
\hline $\mathrm{L} 1_{\mathrm{M}}$ & 4.5 & 2.5 & 2.4 & 1.9 & 3.8 \\
\hline $\mathrm{L} 2 \mathrm{~W}$ & 1.8 & 0.9 & 1.0 & 0.6 & 1.3 \\
\hline $\mathrm{L} 3_{\mathrm{W}}$ & 3.6 & 2.0 & 2.4 & 1.3 & 2.5 \\
\hline Mean & 2.7 & 2.6 & 2.7 & 1.9 & 3.5 \\
\hline \multicolumn{6}{|l|}{ PLP } \\
\hline $\mathrm{K} 1_{\mathrm{M}}$ & 37.5 & 45.1 & 43.0 & 51.6 & 37.5 \\
\hline $\mathrm{K} 2_{\mathrm{M}}$ & 40.2 & 61.0 & 61.8 & 61.8 & 57.5 \\
\hline $\mathrm{K} 3_{\mathrm{W}}$ & 39.3 & 49.8 & 43.0 & 55.4 & 56.3 \\
\hline $\mathrm{L} 1_{\mathrm{M}}$ & 32.1 & 36.7 & 31.9 & 40.1 & 42.5 \\
\hline $\mathrm{L} 2 \mathrm{~W}$ & 17.9 & 27.7 & 22.7 & 30.6 & 35.0 \\
\hline $\mathrm{L} 3_{\mathrm{W}}$ & 46.4 & 46.9 & 43.0 & 52.2 & 46.3 \\
\hline Mean & 35.6 & 44.5 & 40.9 & 48.6 & 45.8 \\
\hline \multicolumn{6}{|l|}{$H^{\prime}$} \\
\hline $\mathrm{K} 1_{\mathrm{M}}$ & 0.22 & 0.25 & 0.24 & 0.29 & 0.19 \\
\hline $\mathrm{K} 2_{\mathrm{M}}$ & 0.26 & 0.34 & 0.35 & 0.34 & 0.29 \\
\hline $\mathrm{K} 3_{\mathrm{W}}$ & 0.15 & 0.23 & 0.22 & 0.24 & 0.25 \\
\hline $\mathrm{L} 1_{\mathrm{M}}$ & 0.19 & 0.19 & 0.17 & 0.20 & 0.24 \\
\hline $\mathrm{L} 2 \mathrm{~W}$ & 0.08 & 0.13 & 0.11 & 0.14 & 0.18 \\
\hline $\mathrm{L} 3_{\mathrm{W}}$ & 0.25 & 0.24 & 0.22 & 0.28 & 0.22 \\
\hline Mean & 0.19 & 0.23 & 0.22 & 0.25 & 0.23 \\
\hline Overall & 0.59 & 0.44 & 0.50 & 0.43 & 0.31 \\
\hline
\end{tabular}

*Numbers in brackets indicate amplified fragment length polymorphisms (AFLP) phenotypes that were shared by more than one individual. $P L P$, percentage of polymorphic loci $\left(P L P_{\text {gen }}\right)$ and epiloci $\left[P L P_{\text {epi }}\right] ; H^{\prime}$, Shannon's information index $\left(H^{\prime}\right.$ gen for genetic data and $H^{\prime}$ epi for epigenetic data).

The MSAP analysis resulted in 555 scorable epiloci of which 275 (49.5\%) were polymorphic. These polymorphic epiloci yielded 444 polymorphic subepiloci, consisting of $207 \mathrm{n}$-, $157 \mathrm{~m}$ - and 80 h-subepiloci. $42.9 \%$ of all epiloci resulted in only one subepilocus type (19.3\%, $11.3 \%$ and $12.4 \%$ for $\mathrm{n}-, \mathrm{m}$ - and h-subepiloci, respectively), $40.4 \%$ in $n-$ and m-subepiloci, $11.2 \%$ in $n-$ and h-subepiloci, $1.1 \%$ in $\mathrm{m}$ - and h-subepiloci and $4.4 \%$ yielded all three types of subepiloci. All 132 individuals had unique MSAP phenotypes. Values of diversity for the different subepiloci across populations are given in Table 2. Population-level genetic and epigenetic diversity was significantly correlated (Spearman rank-correlation: $\rho=0.83, P=0.042$ for PLP; $\rho=0.89, P=0.019$ for $H^{\prime}$ ), and epigenetic diversity was or tended to be higher than genetic diversity [paired $t$-test: $t(5)=-3.20$, $P=0.024$ for $P L P ; t(5)=-2.43, P=0.060$ for $\left.H^{\prime}\right]$. 


\section{Genetic and epigenetic structure}

Principal coordinates analysis of genetic distances separated $\mathrm{K}$ - and L-sites, both being further subdivided into two clusters (Fig. 2). Whereas regions were mainly separated along the second coordinate, no grouping for habitat type could be observed.

Principal coordinates analyses of epigenetic distances revealed varying population differentiation patterns among subepiloci (Fig. 2). For n-subepiloci, in contrast to genetic data, $\mathrm{K} 3_{\mathrm{W}}$ was separated from both $\mathrm{K}$-meadow sites that formed two mixed clusters. All L-sites were clearly separated. For m-subepiloci, individuals were less clumped but clustering overall resembled that of n-subepiloci. For both, n- and m-subepiloci habitat types tended to be separated along the first axis. In contrast, for h-subepiloci individuals were widely scattered and without clear population differentiation. When n-, $\mathrm{m}$ - and $\mathrm{h}$-subepiloci were combined in one analysis, similar patterns of population differentiation were found as for $\mathrm{n}$ - and m-subepiloci (data not shown).
Analysis of molecular variance of genetic data revealed a global $\phi_{\mathrm{ST}}$ of 0.72 and pairwise $\phi_{\mathrm{ST}}$ between 0.52 and 0.84 (Table S2, Supporting information), indicating very strong genetic population differentiation. Hierarchical AMOVA (Table 3) showed that $11.6 \%$ of genetic variance resided between regions, but only $2.1 \%$ between habitats. Most variation was partitioned among populations within geographic or habitat groups $(62.1 \%$ and $70.5 \%$, respectively).

For the combined epigenetic data set (Table 3), overall differentiation was lower than for genetic data but still high (global $\phi_{\mathrm{ST}}=0.51$ ), with pairwise population $\phi_{\mathrm{ST}}$ ranging from 0.35 to 0.67 (Table S2, Supporting information). Hierarchical AMOVA revealed that only $1.2 \%$ of epigenetic variance resided between regions, but $6.1 \%$ between habitats. Variation among populations within groups was similar for regions $(49.7 \%)$ and habitats $(45.9 \%)$. Considering $\mathrm{n}-, \mathrm{m}-$ and $\mathrm{h}$-subepiloci separately revealed global $\phi_{\mathrm{ST}}$ values of $0.60,0.46$, and 0.21 , respectively. In all MSAP data sets, stronger

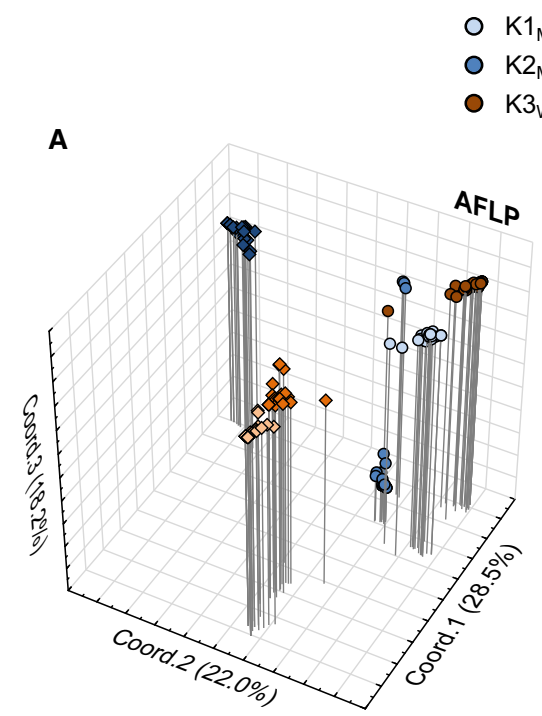

$\begin{array}{llll}\circ & \mathrm{K} 1_{\mathrm{M}} & \diamond & \mathrm{L} 1_{\mathrm{M}} \\ \circ & \mathrm{K} 2_{\mathrm{M}} & \diamond & \mathrm{L} 2_{\mathrm{W}} \\ \circ & \mathrm{K} 3_{\mathrm{W}} & \diamond & \mathrm{L} 3_{\mathrm{W}}\end{array}$
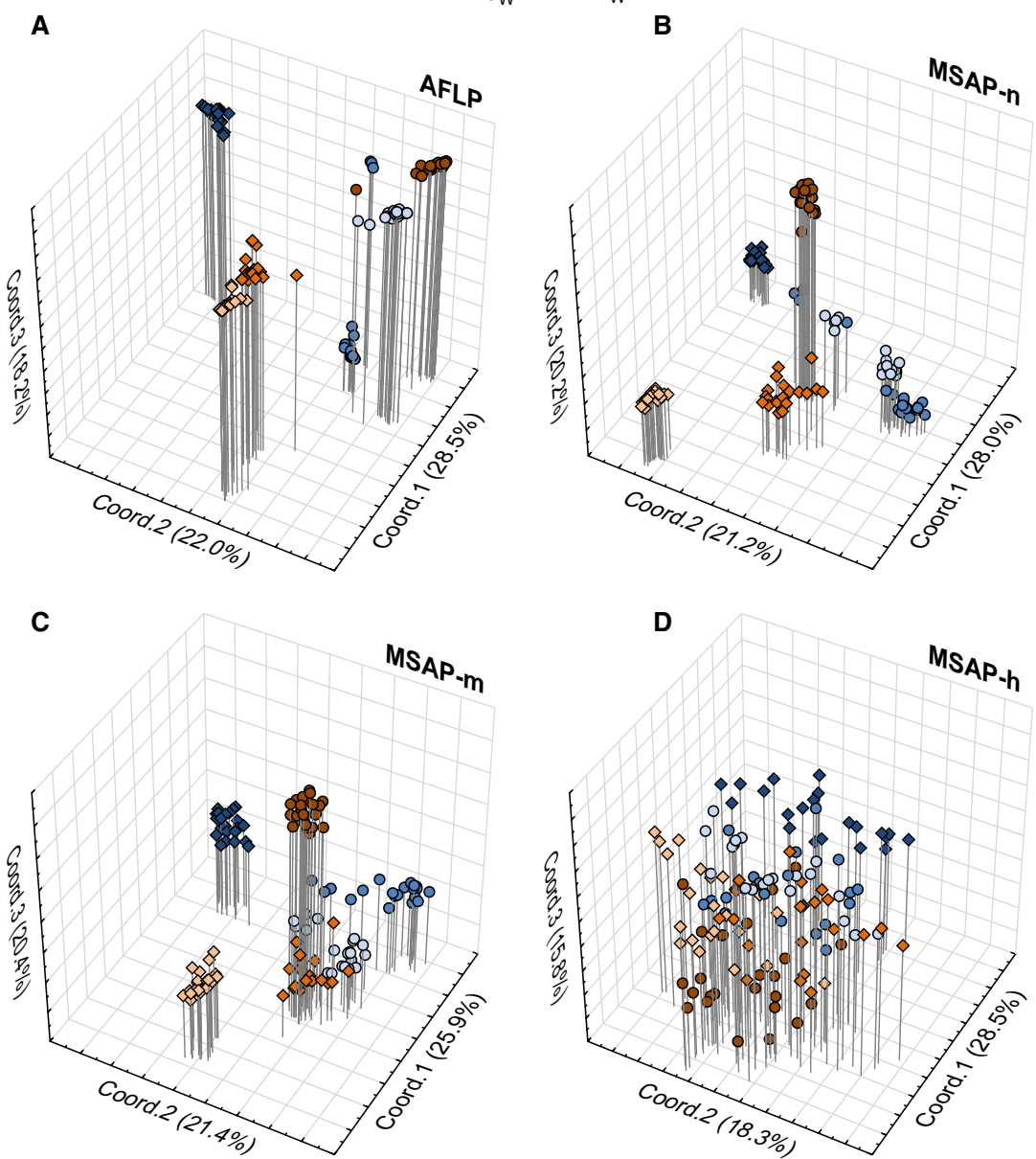

Fig. 2 Principal coordinates analyses (PCoA) of genetic (A) and epigenetic distances (B-D) of six populations of Viola elatior. Epigenetic data were partitioned into the three discriminable methylation types, that is, (B) unmethylated (n), (C) CG-methylated (m) and (D) CHG-hemimethylated (h) subepiloci. Regions are indicated by symbol type (circle $=$ KühkopfKnoblochsaue, diamond $=$ Lampertheimer Altrhein). Habitats are displayed by colour (blue $=$ meadow , brown $=$ woodland $)$. 
differentiation was observed among habitats than among regions, contrary to the AFLP data.

Mantel tests revealed a strong correlation between genetic and epigenetic differentiation ( $r=0.76$, $P<0.005)$. However, no simple isolation-by-distance or isolation-by-habitat pattern was found as no significant relationship existed between genetic or epigenetic differentiation and geographical distance $(P>0.18)$ or habitat similarity $(P>0.1$; Table S3, Supporting information). However, when controlling for geographic distance, habitat similarity was significantly correlated with epigenetic $(P=0.04)$, but not with genetic differentiation $(P=0.30)$.

\section{Outlier detection}

For the AFLP data set, SAM identified 19 (17.0\%) and 17 $(15.2 \%)$ outliers that were associated with light environment at $95 \%$ and $99 \% \mathrm{CI}$, respectively (Table 4, Table S4, Supporting information). In contrast, with both differentiation-based genome scans, the number of genetic outliers was strongly reduced. Whereas DFDIST/ FDIST detected $5(4.5 \%)$ and $1(0.9 \%)$ outliers at $95 \%$ and 99\% CI (Table S4, Supporting information), respectively, no outliers at all were identified by BAYESCAN. Two $(1.8 \%)$ outliers were similarly detected by SAM and DFDIST /FDIST.

Table 3 Hierarchical AMOVA for amplified fragment length polymorphisms (AFLP) and methylation-sensitive amplification polymorphisms (MSAP) data performed by grouping populations according to regions of origin or habitat types

\begin{tabular}{|c|c|c|c|c|c|}
\hline Loci/Groups & Variance components & $\mathrm{V}$ & $\%$ total & $P$ & $\phi$ statistics \\
\hline \multicolumn{6}{|l|}{ AFLP loci (112) } \\
\hline All populations $(n=6)$ & Among all populations & 12.09 & 72.36 & $<0.0001$ & $\phi_{\mathrm{ST}}=0.72$ \\
\hline \multirow[t]{3}{*}{ Regions $(n=2)$} & Among regions & 2.03 & 11.56 & 0.20 & $\phi_{\mathrm{CT}}=0.12$ \\
\hline & Among populations within regions & 10.87 & 62.08 & $<0.0001$ & $\phi_{\mathrm{SC}}=0.70$ \\
\hline & Within populations & 4.62 & 26.36 & $<0.0001$ & $\phi_{\mathrm{ST}}=0.74$ \\
\hline \multirow[t]{3}{*}{ Habitats $(n=2)$} & Among habitats & 0.36 & 2.12 & 0.39 & $\phi_{\mathrm{CT}}=0.02$ \\
\hline & Among populations within habitats & 11.88 & 70.48 & $<0.0001$ & $\phi_{\mathrm{SC}}=0.72$ \\
\hline & Within populations & 4.62 & 27.40 & $<0.0001$ & $\phi_{\mathrm{ST}}=0.73$ \\
\hline \multicolumn{6}{|l|}{ MSAP all subepiloci (444) } \\
\hline All populations $(n=6)$ & Among all populations & 22.87 & 50.73 & $<0.0001$ & $\phi_{\mathrm{ST}}=0.51$ \\
\hline \multirow[t]{3}{*}{ Regions $(n=2)$} & Among regions & 0.56 & 1.24 & 0.50 & $\phi_{\mathrm{CT}}=0.01$ \\
\hline & Among populations within regions & 22.53 & 49.73 & $<0.0001$ & $\phi_{\mathrm{SC}}=0.50$ \\
\hline & Within populations & 22.21 & 49.02 & $<0.0001$ & $\phi_{\mathrm{ST}}=0.51$ \\
\hline \multirow[t]{3}{*}{ Habitats $(n=2)$} & Among habitats & 2.80 & 6.07 & 0.10 & $\phi_{\mathrm{CT}}=0.06$ \\
\hline & Among populations within habitats & 21.19 & 45.86 & $<0.0001$ & $\phi_{\mathrm{SC}}=0.49$ \\
\hline & Within populations & 22.21 & 48.07 & $<0.0001$ & $\phi_{\mathrm{ST}}=0.52$ \\
\hline \multicolumn{6}{|l|}{ MSAP n-subepiloci (207) } \\
\hline All populations $(n=6)$ & Among all populations & 14.77 & 59.87 & $<0.0001$ & $\phi_{\mathrm{ST}}=0.60$ \\
\hline \multirow[t]{3}{*}{ Regions $(n=2)$} & Among regions & 0.43 & 1.75 & 0.39 & $\phi_{\mathrm{CT}}=0.02$ \\
\hline & Among populations within regions & 14.51 & 58.41 & $<0.0001$ & $\phi_{\mathrm{SC}}=0.59$ \\
\hline & Within populations & 9.90 & 39.85 & $<0.0001$ & $\phi_{\mathrm{ST}}=0.60$ \\
\hline \multirow[t]{3}{*}{ Habitats $(n=2)$} & Among habitats & 2.01 & 7.90 & 0.10 & $\phi_{\mathrm{CT}}=0.08$ \\
\hline & Among populations within habitats & 13.56 & 53.24 & $<0.0001$ & $\phi_{\mathrm{SC}}=0.58$ \\
\hline & Within populations & 9.90 & 38.85 & $<0.0001$ & $\phi_{\mathrm{ST}}=0.61$ \\
\hline \multicolumn{6}{|l|}{ MSAP m-subepiloci (157) } \\
\hline All populations $(n=6)$ & Among all populations & 7.02 & 45.67 & $<0.0001$ & $\phi_{\mathrm{ST}}=0.46$ \\
\hline \multirow[t]{3}{*}{ Regions $(n=2)$} & Among regions & 0.27 & 1.78 & 0.49 & $\phi_{\mathrm{CT}}=0.02$ \\
\hline & Among populations within regions & 6.85 & 44.28 & $<0.0001$ & $\phi_{\mathrm{SC}}=0.45$ \\
\hline & Within populations & 8.35 & 53.94 & $<0.0001$ & $\phi_{\mathrm{ST}}=0.46$ \\
\hline \multirow[t]{3}{*}{ Habitats $(n=2)$} & Among habitats & 0.63 & 4.02 & 0.21 & $\phi_{\mathrm{CT}}=0.04$ \\
\hline & Among populations within habitats & 6.64 & 42.53 & $<0.0001$ & $\phi_{\mathrm{SC}}=0.44$ \\
\hline & Within populations & 8.35 & 53.45 & $<0.0001$ & $\phi_{\mathrm{ST}}=0.47$ \\
\hline \multicolumn{6}{|l|}{ MSAP h-subepiloci (80) } \\
\hline All populations $(n=6)$ & Among all populations & 1.08 & 21.45 & $<0.0001$ & $\phi_{\mathrm{ST}}=0.21$ \\
\hline \multirow[t]{3}{*}{ Regions $(n=2)$} & Among regions & -0.15 & -2.92 & 1.00 & $\phi_{\mathrm{CT}}=-0.03$ \\
\hline & Among populations within regions & 1.17 & 23.45 & $<0.0001$ & $\phi_{\mathrm{SC}}=0.23$ \\
\hline & Within populations & 3.97 & 79.47 & $<0.0001$ & $\phi_{\mathrm{ST}}=0.21$ \\
\hline \multirow[t]{3}{*}{ Habitats $(n=2)$} & Among habitats & 0.16 & 3.16 & 0.10 & $\phi_{\mathrm{CT}}=0.03$ \\
\hline & Among populations within habitats & 0.99 & 19.28 & $<0.0001$ & $\phi_{\mathrm{SC}}=0.20$ \\
\hline & Within populations & 3.97 & 77.55 & $<0.0001$ & $\phi_{\mathrm{ST}}=0.22$ \\
\hline
\end{tabular}


For the complete set of the 444 MSAP, subepiloci SAM identified $50(11.3 \%)$ and $30(6.8 \%)$ outliers at 95\% and 99\% CI, respectively (Table 4, Table S5, Supporting information). Related to the original 275 epiloci, 39 $(14.2 \%)$ and $24(8.7 \%)$ of all epiloci resulted in one or two outlier subepiloci at $95 \%$ and $99 \% \mathrm{CI}$, respectively (Table S5, Supporting information). At 95\% CI, the three methylation types contributed differently to outliers as $15.0 \%, 10.2 \%$ and $3.8 \%$ of the $\mathrm{n}-, \mathrm{m}-$ and h-subepiloci, respectively, revealed signatures of adaptation $\left(\chi^{2}=6.21, P=0.045\right)$.

Comparing PCoA patterns of neutral and outlier markers separately revealed strong differences between marker groups (Fig. 3). For neutral markers, overall population structuring was very similar between AFLP and MSAP data, dividing regions along a diagonal between the first and second axes. In contrast, for outlier markers, only epigenetic data clearly separated habitat types. Moreover, whereas for AFLP data, all meadow populations formed individual clusters along the second axis and regions still tended to be separated, for MSAP data, meadow populations formed one larger cluster that only showed some variation along the third axis.

\section{Behaviour of subepilocus outliers}

For most m-subepiloci identified as outliers by SAM, the corresponding n-subepiloci were identified as outliers (11/16 for $95 \%$ CI; $6 / 7$ for $99 \% \mathrm{CI})$, that is, both the $n-$ and m-subepilocus derived from the same MSAP epilocus were putatively adaptive (Table S5, Supporting information). Interestingly, all putatively adaptive n-/ m-subepilocus pairs identified by SAM had reciprocal epigenotypes at low and high light conditions. For example, epilocus ACA_TCCA_188 was always nonmethylated in woodland sites, whereas in meadow sites it was mainly CG-methylated (Fig. 4). Strikingly, almost all identified light-related n-/m-pairs (9/11 for $95 \% \mathrm{CI}$; $5 / 6$ for $99 \%$ CI) were similarly associated with woodland and meadow sites, respectively. Moreover, in the complete set of SAM outliers (99\% CI), significantly more n-subepiloci were associated with low light availability

Table 4 Numbers of amplified fragment length polymorphisms (AFLP) and methylation-sensitive amplification polymorphisms (MSAP) outlier (epi)loci for six populations of Viola elatior as assessed by Spatial Analysis Method (SAM) analyses for correlation with light environment

\begin{tabular}{llllll}
\hline & AFLP & MSAP all & MSAP n & MSAP m & MSAP h \\
\hline SAM 95\% CI & 19 & 50 & 31 & 16 & 3 \\
SAM 99\% CI & 17 & 30 & 20 & 7 & 3 \\
\hline
\end{tabular}

than expected (17 of 20 for 99\% CI; $\chi^{2}$-test with Yates continuity correction: $\chi^{2}=4.10, P=0.043$ ).

\section{Discussion}

Epigenetic modifications, such as DNA methylation, may play a pivotal role in the response of plant populations to environmental change (Bossdorf et al. 2008; Sahu et al. 2013). Additionally, due to their potential inheritance, it was proposed that epigenetic marks can be under selection and even might impact evolution (Richards 2006; Angers et al. 2010; Flatscher et al. 2012). However, directly testing epigenetic adaptation in natural populations is challenging, as the adaptive value of epigenetic variation is hard to proof under complex and dynamic environmental conditions and in the presence of genetic variation. Here, we used an indirect approach to assess the putative contribution of genetic and epigenetic variation in populations of $V$. elatior to environmental adaptation along a light gradient by comparing genetic and epigenetic population structure and applying a correlation-based outlier approach.

\section{Genetic and epigenetic diversity}

The AFLP analysis revealed low levels of genetic diversity both overall and within populations of $V$. elatior. This is consistent with findings for other mixed mating plant species with predominant CL seed production (Sun 1999; Durka et al. 2012), showing strong inbreeding, little or no genetic variability within populations and strong population differentiation (Culley \& Wolfe 2001). In the case of the rare $V$. elatior, additional factors like spatial isolation and past population bottlenecks may have aggravated this pattern. Epigenetic diversity, although in most populations slightly higher, in general was comparable to genetic diversity among populations, resulting in a significant correlation of genetic and epigenetic diversity estimates. This implies that epigenetic diversity largely depends on genetic diversity and at least partially underlies the same driving forces. Other studies surveying nonclonal species also observed equal or higher epigenetic than genetic diversity (Herrera \& Bazaga 2010; Lira-Medeiros et al. 2010; Abratowska et al. 2012; Wu et al. 2013), suggesting that this is a common pattern in genetically diverse plant species.

For $V$. elatior, neither habitat nor region had a profound effect on genetic or epigenetic diversity and only very small population size $(\mathrm{L} 2 \mathrm{~W})$ markedly reduced diversity. In contrast, previous epigenetic studies that investigated populations from different environments (Lira-Medeiros et al. 2010; Abratowska et al. 2012; Wu et al. 2013) found significant differences between habitats. This might have two reasons: first, these 


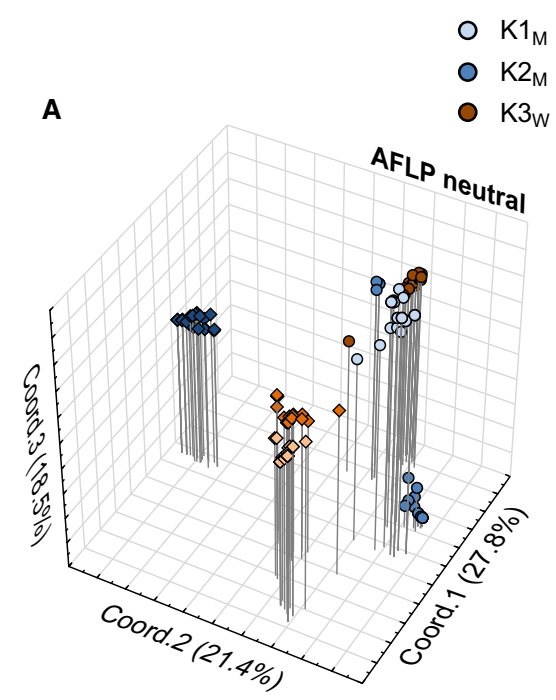

$$
\begin{array}{llll}
\circ & \mathrm{K} 1_{\mathrm{M}} & \diamond & \mathrm{L} 1_{\mathrm{M}} \\
\circ & \mathrm{K} 2_{\mathrm{M}} & \diamond & \mathrm{L} 2_{W} \\
\circ & \mathrm{K} 3_{W} & \diamond & L 3_{W}
\end{array}
$$
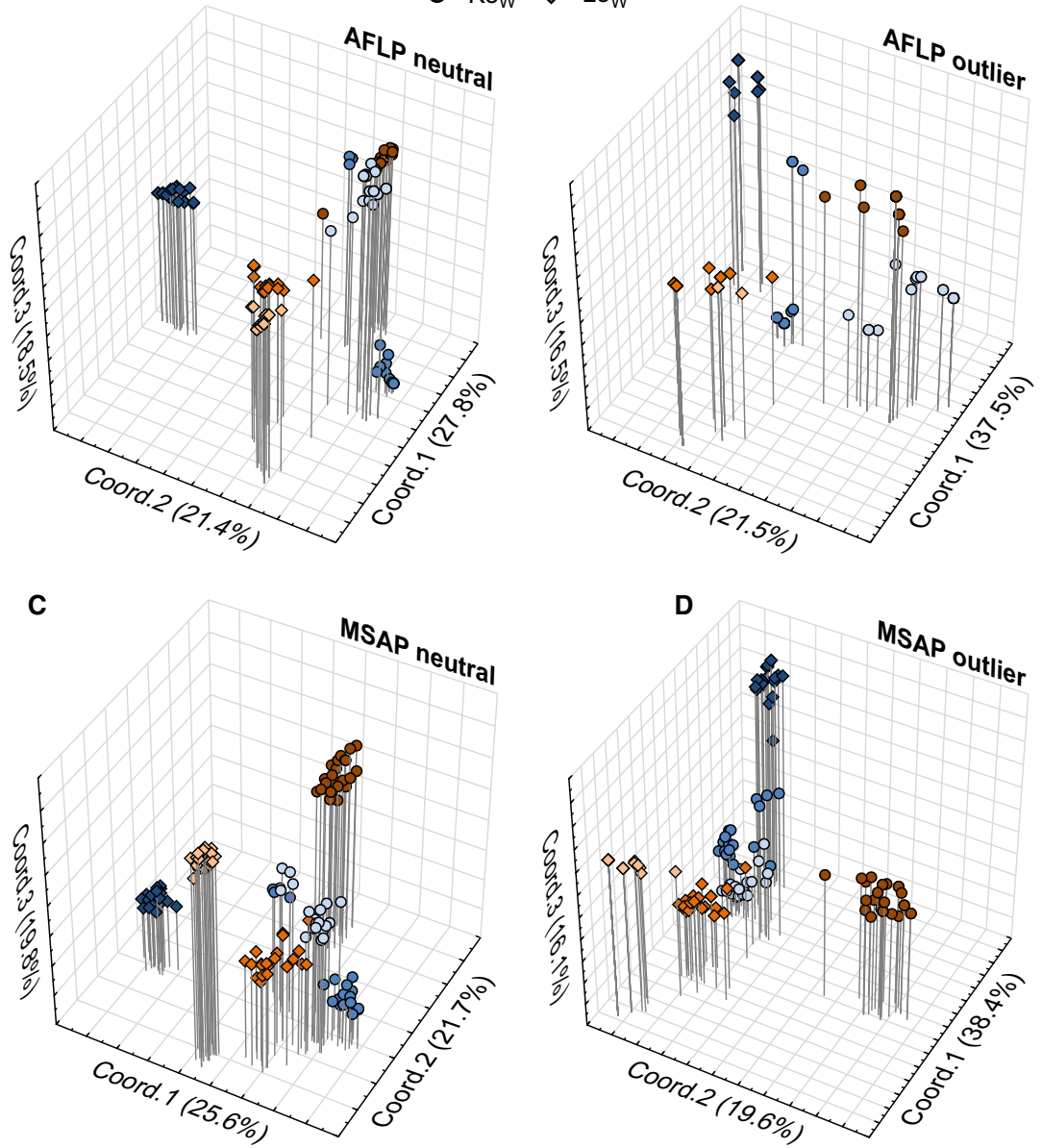

Fig. 3 Principal coordinates analyses (PCoA) of genetic (A, B) and epigenetic $(C, D)$ distances of neutral and outlier (subepi)loci as assessed by SAM for correlation with light availability. For legend, see Fig. 2. studies compared spatially and temporally stable environments instead of relatively dynamic habitat types along a successional gradient. If a less favourable habitat is associated with elevated levels of environmental stress that may lead to genome instability and higher mutation rates, under constant conditions this could be the driving force for an increase in genetic diversity (Wu et al. 2013), whereas under dynamic conditions this effect would be outbalanced between habitats or would only act for relatively short periods of time. Second, $V$. elatior possesses a long-lived persistent soil seed bank (Eckstein et al. 2006). Through continuous recruitment of genotypes from past generations, the seed bank may buffer temporal variation in genetic diversity (Honnay et al. 2008).

\section{Genetic and epigenetic structure}

At the genetic level, $V$. elatior showed very strong population differentiation $\left(\phi_{\mathrm{ST}}=0.72\right)$ reflecting high selfing rates and small population sizes resulting in genetic drift. This is further corroborated by a lack of correlation between genetic differentiation and geographic distances indicating that spatial isolation did not play the major role for population differentiation.

Although there was a positive correlation between epigenetic and genetic distances, epigenetic population differentiation compared with genetic differentiation was markedly reduced and more closely related to habitat conditions. This indicates that environmentally induced changes in methylation patterns may lead to a convergence of populations experiencing similar habitat conditions and thus counteract effects of historical demographic processes. Moreover, as revealed by PCoA, the different subepiloci types contributed differently to population structure, suggesting that the two methylation types distinguished (i.e. CG-methylation and CHG-hemimethylation), possess different functional roles. Whereas both, $\mathrm{n}$ - and m-subepiloci similarly separated the habitat types, h-subepiloci revealed hardly any population structure. This indicates that regulation of gene function by methylation or 

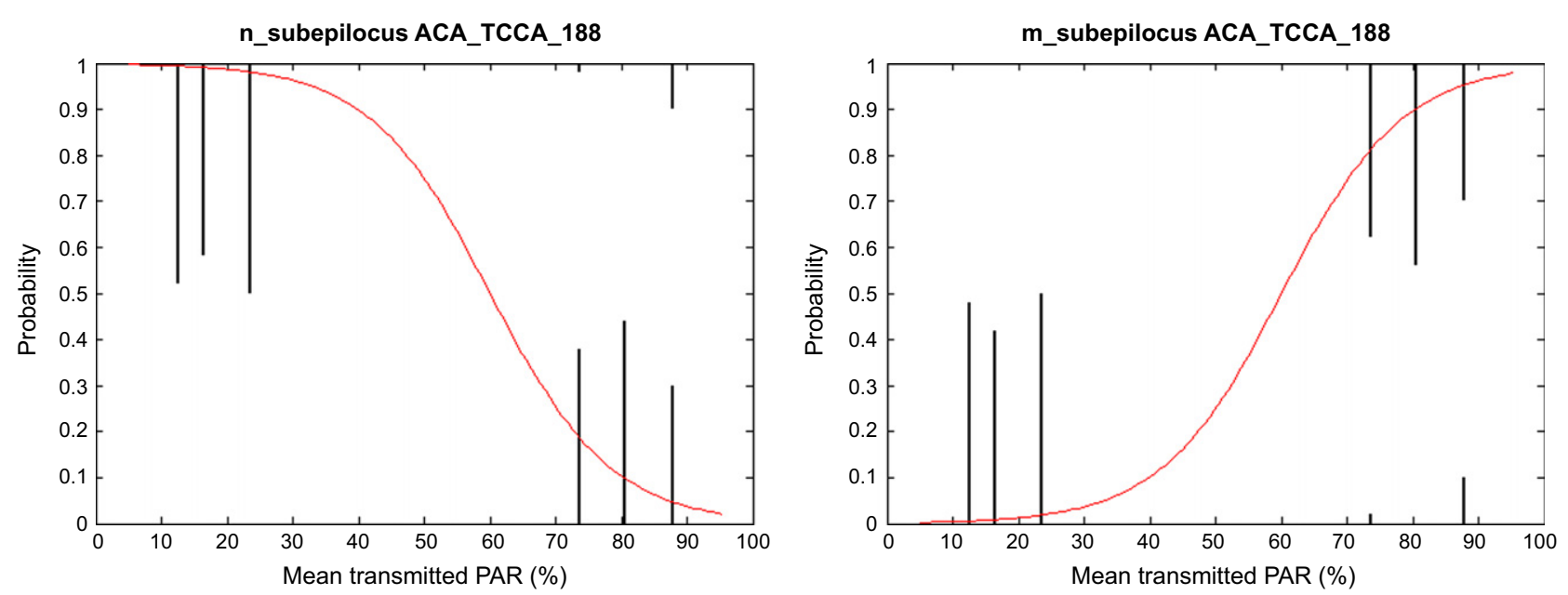

Fig. 4 Example of two corresponding outlier subepiloci, illustrating a putatively adaptive epigenetic switch mechanism. The probability of band presence/absence of both, $\mathrm{n}$ - and m-subepilocus of the methylation-sensitive amplification polymorphisms (MSAP) marker ACA_TCCA_188 are significantly associated with mean percentage of transmitted photosynthetic-active radiation (PAR). The graphs show the logistic sigmoid function of marker presence vs. the mean light availability at the sampling sites. At low light (woodland), the marker ACA_TCCA_188 is found to be completely unmethylated, while at high light (meadow) nearly all individuals show a CG-methylation. Bars represent the number of present (top) and absent (bottom) bands for each of the six surveyed populations.

demethylation in the CG-context plays a more important role for habitat adjustment than changes of hemimethylation in the CHG-context. A functional difference between the two methylation types is further supported by the observation that of all polymorphic epiloci only $5.5 \%$ included both fragment types, whereas $51.7 \%$ and $23.6 \%$ included methylations either only in the CG- or CHG-context, respectively. These findings clearly show the need for separate analyses of CG- and CHG-methylated states, which are rarely distinguished in epigenetic population studies (but see Salmon et al. 2008; Paun et al. 2010).

\section{Outlier detection}

Outlier detection is a widely used approach to analyse putative selection processes using anonymous genetic marker data. However, genome scan approaches have been rarely used for MSAP data (Paun et al. 2010; Schrey et al. 2012), which may reflect the uncertainty if the central underlying assumption is valid for methylation variation, namely that heritable marker loci give rise to phenotypes which are targets of natural selection leading to change in frequencies of adaptive markers. First, epigenetic variation may depend on genetic variation (i.e. obligatory and facilitated epigenetic variation sensu Richards 2006). Hence, it is impossible to distinguish whether a certain epigenetic state or any underlying causative genetic state is putatively under selection. Second, epigenetic variation can be either generated randomly (epimutation) or environmentally induced, which has different implications for selection processes (Shea et al. 2011; Verhoeven \& Preite 2014) and thus their detectability. Third, epigenetic variation can have different degrees of transgenerational stability (Herman et al. 2014), ranging from transient changes, over short-term (i.e. across two generations) to long-term heritable changes (i.e. several generations). The traditional view is that adaptive traits are selected for by natural selection only if traits are heritable. Thus, the degree of epigenetic heritability will impact the selective outcome. However, if over a long time, the same advantageous phenotype arises every generation by transient epigenetic modifications it will also be selected for. Recent theory (Herman et al. 2014) and some first evidence in natural populations (Herrera et al. 2014) suggest that epigenetic stability itself is a selective trait, thus introducing another layer of complexity to the system. Lastly, in outlier locus analyses, AFLP loci are used as markers that can track differentiation based on selection at linked loci. In contrast, the epigenetic interpretation of MSAP outlier loci is different as it must be assumed that the MSAP locus itself is causal to function. Taken together, epigenetic variation does not easily fit into the hitherto existing framework of selection and adaptation and thus may not easily be suited for classical differentiation-based genome scan analyses. This notwithstanding, correlation-based genome scan approaches like SAM, which are largely assumption free, still offer a good opportunity to study putatively 
adaptive methylation variation in relationship to environmental conditions.

Spatial Analysis Method analyses of $V$. elatior populations resulted in comparable percentages of light-related outlier markers for genetic (17.0\%) and epigenetic (14.2\%) data. Given the limited power to detect significant marker associations due to the relative small number of surveyed populations and the use of averaged light values for all individuals from one site, the results imply that both levels of variation may play an important role for habitat-related adaptation. However, as revealed by differentiation-based genome scan approaches, for AFLP data, the percentage of genetic outliers was strongly reduced and only very few of the SAM outliers (two of 19) actually seemed to be under positive selection. Moreover, with DFDIST/FDIST (4.5\%) and BAYESCAN $(0 \%)$, the percentage of genetic outliers was strongly reduced, thus questioning a large impact of genetic selection. In contrast, PCoA results for neutral and outlier MSAP markers strongly support the hypothesis that methylation variation plays a major role in response to habitat conditions. Whereas for neutral markers, genetic and epigenetic population structure were almost identical, for outlier markers only epigenetic variation led to a close clustering of the genetically well differentiated meadow populations. Interestingly, such clustering was not observed for woodland populations, suggesting that this habitat is more heterogeneous and thus entailing higher differentiation in response to other environmental parameters than light. A stronger habitat-related impact of epigenetic variation is furthermore corroborated by the results of partial Mantel tests, showing that when controlling for geographical distance, only epigenetic but not genetic variation was significantly correlated with habitat similarity.

There is rising evidence from experimental studies that large proportions of stress-induced changes in epigenetic variation may be heritable across generations (Verhoeven et al. 2010; Kou et al. 2011). Verhoeven et al. (2010) found that ecological stressors led to methylation changes of $15-30 \%$ of polymorphic epiloci in apomictic dandelions. Strikingly, the vast majority of methylation changes (74-92\%) were faithfully transmitted to the unstressed progeny and only a small proportion reverted back to the original state. Comparably high percentages of inheritance of methylation polymorphisms (75\%) and subsequent persistence of multilocus epigenetic differentiation occurred in populations of Helloborus foetidus (Herrera et al. 2013). Thus, it seems plausible that also in the case of $V$. elatior a considerable amount of the epigenetic outliers detected by SAM are heritable and hence might enable 'soft inheritance'. However, as we surveyed only one generation of plants, our study cannot distinguish whether the observed epigenetic correlation with habitats reflects epigenetically mediated within-generation phenotypic plasticity or indeed heritable adaptations.

\section{Behaviour of subepilocus outliers}

Our scoring approach allowed us to differentiate individual MSAP fragment types. The finding that at $95 \%$ CI only $3.8 \%$ of the h-subepiloci, but $10.2 \%$ of the msubepiloci were detected as outliers further indicates functional differences between the two methylation types. Even more interesting was the observation that the vast majority of outliers were n-subepiloci $(15 \%$ of all n-subepiloci), suggesting that primarily the demethylated and thus probably active state of an epilocus is correlated with specific environmental conditions. This is corroborated by the fact that for almost all m-subepiloci outliers also the corresponding n-subepiloci were outliers.

Of the outliers identified by SAM most n-subepiloci were related to low light and most m-subepiloci to high light, indicating a directional epigenetic regulation mechanism. Especially, the corresponding $n$ - and m-subepiloci outliers suggest a switch mechanism that activates stress-related genes by demethylation under low-light conditions and downregulates them by methylation under high light conditions. Indeed, biotic and abiotic stressors can induce selective demethylation processes and transcriptional activation of stress-related genes (Wada et al. 2004; Choi \& Sano 2007). Moreover, global hypomethylation may be a response to environmental stressors (e.g. Zhong et al. 2009; Wang et al. 2011) or different habitats (Lira-Medeiros et al. 2010; Wu et al. 2013). However, stress-induced DNA hypermethylation has been observed, too (Labra et al. 2002; Lu et al. 2007) and also the few studies specifically addressing the effects of light availability are equivocal: whereas reduction of light led to genome hypermethylation in seagrass (Greco et al. 2013), low R/FR ratios as a signal of foliage shade resulted in genome hypomethylation in Stellaria longipes (Tatra et al. 2000). Additionally, demethylation was a crucial factor controlling stem elongation (Tatra et al. 2000) and thus might trigger shade-avoidance responses. Overall, our results indicate that while demethylation is a common response to stress, species-specific and stress-specific responses are to be expected.

\section{Conclusions}

The results of our study suggest that DNA methylation variation plays a decisive role in the response of $V$. elatior to changing light conditions. Epigenetic population differentiation was more strongly related to habitat types than was genetic differentiation and epigenetic 
outlier loci led to a stronger habitat related population clustering than genetic outlier loci. This implies that under dynamic conditions the environmental shaping of the epigenome is a stronger force than selection changing the genome. Especially for rare and inbreeding species like $V$. elatior suffering from spatial isolation and small population sizes, genetically independent adaptive epigenetic variation may facilitate long-term population survival in dynamic and strongly contrasting habitats. Thus, provided that epigenetic variation is heritable, 'soft inheritance', that is, environmentally induced methylation change, represents an alternative system to classical 'hard inheritance'.

The application of a novel MSAP-scoring approach revealed new insights into the contribution of methylation types to population differentiation and potential habitat-related adaptation. Using a pure methylationscoring approach would have obscured the association between the environment and demethylated fragments, thus missing information about the putative transcriptional active part of the epigenome, as well as about corresponding outlier pairs that may represent an epigenetic switch mechanism. Future epigenetic population studies using mixed scoring approaches will give further insights into the interplay of methylation types and will show if the differences observed in this study represent a general epigenetic pattern under contrasting environmentally conditions.

\section{Acknowledgements}

We want to thank Josef Scholz vom Hofe and Lena Föhr for help during field work, and Aurélie Bonin, Ovidiu Paun and two anonymous reviewers for valuable comments on the manuscript. Financial support was obtained from the Deutsche Forschungsgemeinschaft (DFG, grant EC209/7-1).

\section{References}

Abratowska A, Wasowicz P, Bednarek PT, Telka J, Wierzbicka M (2012) Morphological and genetic distinctiveness of metallicolous and non-metallicolous populations of Armeria maritima s.l. (Plumbaginaceae) in Poland. Plant Biology, 14, 586595.

Angers B, Castonguay E, Massicotte R (2010) Environmentally induced phenotypes and DNA methylation: how to deal with unpredictable conditions until the next generation and after. Molecular Ecology, 19, 1283-1295.

Antao T, Beaumont MA (2011) Mcheza: a workbench to detect selection using dominant markers. Bioinformatics, 27, 17171718 .

Beaumont MA, Balding DJ (2004) Identifying adaptive genetic divergence among populations from genome scans. Molecular Ecology, 13, 969-980.

Berger SL (2007) The complex language of chromatin regulation during transcription. Nature, 447, 407-412.
Bonin A, Ehrich D, Manel S (2007) Statistical analysis of amplified fragment length polymorphism data: a toolbox for molecular ecologists and evolutionists. Molecular Ecology, 16, 3737-3758.

Bossdorf O, Richards CL, Pigliucci M (2008) Epigenetics for ecologists. Ecology Letters, 11, 106-115.

Boyko A, Kovalchuk I (2011) Genome instability and epigenetic modification-heritable responses to environmental stress? Current Opinion in Plant Biology, 14, 260-266.

Boyko A, Blevins T, Yao Y et al. (2010) Transgenerational adaptation of Arabidopsis to stress requires DNA methylation and the function of Dicer-like proteins. PLoS ONE, 5, e9514.

Bräutigam K, Vining KJ, Lafon-Placette C et al. (2013) Epigenetic regulation of adaptive responses of forest tree species to the environment. Ecology and Evolution, 3, 399-415.

Castonguay E, Angers B (2012) The key role of epigenetics in the persistence of asexual lineages. Genetics Research International, 2012, 1-9.

Choi C-S, Sano H (2007) Abiotic-stress induces demethylation and transcriptional activation of a gene encoding a glycerophosphodiesterase-like protein in tobacco plants. Molecular Genetics and Genomics, 277, 589-600.

Correia B, Valledor L, Meijón M et al. (2013) Is the interplay between epigenetic markers related to the acclimation of cork oak plants to high temperatures? PLOS ONE, 8, e53543.

Culley TM, Wolfe AD (2001) Population genetic structure of the cleistogamous plant species Viola pubescens Aiton (Violaceae), as indicated by allozyme and ISSR molecular markers. Heredity, 86, 545-556.

Durka W, Nossol C, Welk E et al. (2012) Extreme genetic depauperation and differentiation of both populations and species in Eurasian feather grasses (Stipa). Plant Systematics and Evolution, 299, 259-269.

Eckstein RL, Otte A (2005) Effects of cleistogamy and pollen source on seed production and offspring performance in three endangered violets. Basic and Applied Ecology, 6, 339 350.

Eckstein RL, Hölzel N, Danihelka J (2006) Biological Flora of Central Europe: Viola elatior, V. pumila and V. stagnina. Perspectives in Plant Ecology, Evolution and Systematics, 8, 45-66.

Excoffier L, Lischer H (2010) Arlequin suite ver 3.5: a new series of programs to perform population genetics analyses under Linux and Windows. Molecular Ecology Resources, 10, 564-567.

Feng S, Jacobsen SE, Reik W (2010) Epigenetic reprogramming in plant and animal development. Science, 330, 622-627.

Flatscher R, Frajman B, Schönswetter P, Paun O (2012) Environmental heterogeneity and phenotypic divergence: can heritable epigenetic variation aid speciation? Genetics Research International, 2012, 1-9.

Flores KB, Wolschin F, Amdam GV (2013) The role of methylation of DNA in environmental adaptation. Integrative and Comparative Biology, 53, 359-372.

Foll M, Gaggiotti O (2008) A genome-scan method to identify selected loci appropriate for both dominant and codominant markers: a Bayesian perspective. Genetics, 180, 977-993.

Frazer GW, Canham CD, Lertzman KP (1999) Gap Light Analyzer (GLA), Version 2.0: Imaging Software to Extract Canopy Structure and Gap Light Transmission Indices from True-Colour Fisheye Photographs, Users Manual and Program Documentation. 
Simon Fraser University, Burnaby, British Columbia, Canada; and Institute of Ecosystem, Millbrook, New York.

Greco M, Chiappetta A, Bruno L, Bitonti M (2013) Effects of light deficiency on genome methylation in Posidonia oceanica. Marine Ecology Progress Series, 473, 103-114.

Herman JJ, Spencer HG, Donohue K, Sultan SE (2014) How stable "should" epigenetic modifications be? Insights from adaptive plasticity and bet hedging. Evolution, 68, 632-643.

Herrera CM, Bazaga P (2010) Epigenetic differentiation and relationship to adaptive genetic divergence in discrete populations of the violet Viola cazorlensis. New Phytologist, 187, 867-876.

Herrera CM, Bazaga P (2013) Epigenetic correlates of plant phenotypic plasticity: DNA methylation differs between prickly and nonprickly leaves in heterophyllous Ilex aquifolium (Aquifoliaceae) trees. Botanical Journal of the Linnean Society, 171, 441-452.

Herrera CM, Medrano M, Bazaga P (2013) Epigenetic differentiation persists after male gametogenesis in natural populations of the perennial herb Helleborus foetidus (Ranunculaceae). PLoS ONE, 8, e70730.

Herrera CM, Medrano M, Bazaga P (2014) Variation in DNA methylation transmissibility, genetic heterogeneity and fecundity-related traits in natural populations of the perennial herb Helleborus foetidus. Molecular Ecology, 23, 1085-1095.

Honnay O, Bossuyt B, Jacquemyn H, Shimono A, Uchiyama K (2008) Can a seed bank maintain the genetic variation in the above ground plant population? Oikos, 117, 1-5.

Jablonka E, Raz G (2009) Transgenerational epigenetic inheritance: prevalence, mechanisms, and implications for the study of heredity and evolution. The Quarterly Review of Biology, 84, 131-176.

Joost S, Bonin A, Bruford MW et al. (2007) A spatial analysis method (SAM) to detect candidate loci for selection: towards a landscape genomics approach to adaptation. Molecular Ecology, 16, 3955-3969.

Kou HP, Li Y, Song XX et al. (2011) Heritable alteration in DNA methylation induced by nitrogen-deficiency stress accompanies enhanced tolerance by progenies to the stress in rice (Oryza sativa L.). Journal of Plant Physiology, 168, 1685-1693.

Labra M, Ghiani A, Citterio S et al. (2002) Analysis of cytosine methylation pattern in response to water deficit in pea root tips. Plant Biology, 4, 694-699.

Latzel V, Allan E, Bortolini Silveira A et al. (2013) Epigenetic diversity increases the productivity and stability of plant populations. Nature Communications, 4, 2875. doi:10.1038/ ncomms 3875 .

Ledon-Rettig CC (2013) Ecological epigenetics: an introduction to the symposium. Integrative and Comparative Biology, 53, 307-318.

Legendre P, Legendre L (1998) Numerical Ecology. Elsevier Science, Amsterdam.

Lira-Medeiros CF, Parisod C, Fernandes RA et al. (2010) Epigenetic variation in mangrove plants occurring in contrasting natural environment. PLOS ONE, 5, e10326.

Lu G, Wu X, Chen B, Gao G, Xu K (2007) Evaluation of genetic and epigenetic modification in rapeseed (Brassica napus) induced by salt stress. Journal of Integrative Plant Biology, 49, 1599-1607.

Mougel C, Thioulouse J, Perri G, Nesme X (2002) A mathematical method for determining genome divergence and species delineation using AFLP. International Journal of Systematic and Evolutionary Microbiology, 52, 573-586.

Nobis M, Hunziker U (2005) Automatic thresholding for hemispherical canopy-photographs based on edge detection. Agricultural and Forest Meteorology, 128, 243-250.

Oksanen J, Kindt R, Legendre P et al. (2007) vegan: Community ecology package version 1.15-1. Available from http://www. r-project.org.

Paun O, Bateman RM, Fay MF et al. (2010) Stable epigenetic effects impact adaptation in allopolyploid orchids (Dactylorhiza: Orchidaceae). Molecular Biology and Evolution, 27, 2465-2473.

Peakall ROD, Smouse PE (2006) GENALEX 6: genetic analysis in Excel. Population genetic software for teaching and research. Molecular Ecology Notes, 6, 288-295.

Richards EJ (2006) Inherited epigenetic variation-revisiting soft inheritance. Nature Reviews Genetics, 7, 395-401.

Richards CL, Schrey AW, Pigliucci M (2012) Invasion of diverse habitats by few Japanese knotweed genotypes is correlated with epigenetic differentiation. Ecology Letters, 15, 1016-1025.

Sahu PP, Pandey G, Sharma N et al. (2013) Epigenetic mechanisms of plant stress responses and adaptation. Plant Cell Reports, 32, 1151-1159.

Salmon A, Clotault J, Jenczewski E, Chable V, ManzanaresDauleux MJ (2008) Brassica oleracea displays a high level of DNA methylation polymorphism. Plant Science, 174, 61-70.

Saze H, Tsugane K, Kanno T, Nishimura T (2012) DNA methylation in plants: relationship to small RNAs and histone modifications, and functions in transposon inactivation. Plant and Cell Physiology, 53, 766-784.

Schrey AW, Coon CAC, Grispo MT et al. (2012) Epigenetic variation may compensate for decreased genetic variation with introductions: a case study using house sparrows (Passer domesticus) on two continents. Genetics Research International, 2012, 1-7.

Schulz B, Eckstein RL, Durka W (2013) Scoring and analysis of methylation-sensitive amplification polymorphisms for epigenetic population studies. Molecular Ecology Resources, 13, 642-653.

Shea N, Pen I, Uller T (2011) Three epigenetic information channels and their different roles in evolution: epigenetic mechanisms and evolution. Journal of Evolutionary Biology, 24, 1178-1187.

Sun M (1999) Cleistogamy in Scutellaria indica (Labiatae): effective mating system and population genetic structure. Molecular Ecology, 8, 1285-1295.

Tatra GS, Miranda J, Chinnappa CC, Reid DM (2000) Effect of light quality and 5-azacytidine on genomic methylation and stem elongation in two ecotypes of Stellaria longipes. Physiologia Plantarum, 109, 313-321.

Verhoeven KJF, Preite V (2014) Epigenetic variation in asexually reproducing organisms. Evolution, 68, 644-655.

Verhoeven KJF, Jansen JJ, Van Dijk PJ, Biere A (2010) Stressinduced DNA methylation changes and their heritability in asexual dandelions. New Phytologist, 185, 1108-1118.

Wada Y, Miyamoto K, Kusano T, Sano H (2004) Association between up-regulation of stress-responsive genes and hypomethylation of genomic DNA in tobacco plants. Molecular Genetics and Genomics, 271, 658-666.

Wang W, Zhao X, Pan Y et al. (2011) DNA methylation changes detected by methylation-sensitive amplified 
polymorphism in two contrasting rice genotypes under salt stress. Journal of Genetics and Genomics, 38, 419-424.

Wu W-Q, Yi MR, Wang X-F et al. (2013) Genetic and epigenetic differentiation between natural Betula ermanii (Betulaceae) populations inhabiting contrasting habitats. Tree Genetics $\mathcal{E}$ Genomes, 9, 1321-1328.

Yu Y, Yang X, Wang H et al. (2013) Cytosine methylation alteration in natural populations of Leymus chinensis induced by multiple abiotic stresses. PLoS ONE, 8, e55772.

Zhang Y, Chen JM, Millerb JR (2005) Determining digital hemispherical photograph exposure for leaf area index estimation. Agricultural and Forest Meteorology, 133, 166-181.

Zhang Y-Y, Fischer M, Colot V, Bossdorf O (2013) Epigenetic variation creates potential for evolution of plant phenotypic plasticity. New Phytologist, 197, 314-322.

Zhong X, Wang Y, Liu X et al. (2009) DNA methylation polymorphism in annual wild soybean (Glycine soja Sieb. et Zucc.) and cultivated soybean (G. max L. Merr.). Canadian Journal of Plant Science, 89, 851-863.

B.S., R.L.E. and W.D. designed research; B.S. and R.L.E. performed field work; B.S. and W.D. performed laboratory work; B.S. analysed data and wrote the manuscript with contributions from W.D. and R.L.E.

\section{Data accessibility}

Grid maps with individual sample and hemispherical photography coordinates, and AFLP and MSAP data are deposited at the Dryad repository under the accession doi:10.5061/dryad.m1b66.

\section{Supporting information}

Additional supporting information may be found in the online version of this article.

Appendix S1 AFLP and MSAP protocol.

Table S1 Adaptor and primer sequences used for AFLP and MSAP analyses.

Table S2 Pairwise population $\phi_{\mathrm{ST}}$ for AFLP loci and MSAP subepiloci.

Table S3 Results of simple and partial Mantel tests for genetic and epigenetic pairwise population $\phi_{\mathrm{ST}}$ with geographic distance and habitat matrices.

Table S4 Detailed list of AFLP outlier loci.

Table S5 Detailed list of MSAP outlier subepiloci. 